\title{
THE TUCKMAN'S MODEL IMPLEMENTATION, EFFECT, AND ANALYSIS \& THE NEW DEVELOPMENT OF JONES LSI MODEL ON A SMALL GROUP
}

\author{
Dr. Alex Jones \\ Professor of Leadership, College of Business Administration \\ American University in the Emirates (AUE) \\ Dubai, United Arab Emirates
}

\begin{abstract}
This paper presents a practical overview of the implementation of Tuckman model created by Bruce W. Tuckman in 1965 and revised by Tuckman and Mary Ann Conover Jensen in 1977. The model reflects the stages of forming, storming, norming, performing, and adjourning on group dynamics on a small group of graduate students studying business major at the American University in the Emirates. The stages reflect the impact of the model while students conducting a negotiation role-play in a class setting composed of young leaders. The findings reflect the practicality of such a model to academia and practitioners in the workplace. The outcome of this study has revealed a new Jones LSI model that has a significant value to organizations facing the increasing today's challenges.
\end{abstract}

Keywords: Tuckman Model, Jones LSI model, Groups, Negotiation

Cite this Article: Dr. Alex Jones, The Tuckman's Model Implementation, Effect, and Analysis \& the New Development of Jones LSI Model on a Small Group. Journal of Management, 6(4), 2019, pp. 23-28.

http://www.iaeme.com/jom/issues.asp?JType=JOM\&VType=6\&IType=4

\section{INTRODUCTION}

The complexity of our world today is increasing. Organizations are going through lots of changes. Some of which are transactional and others are transformational. The structure of organizations varies from one to another. Regardless of such the use of a certain model can impact the process of implementation to certain extents. Therefore, a use of a specific model can play a major role in the organization of such tasks.

The Tuckman's Model has become one of the most influential and well recognized. It was first published in the year of 1965 and has become the most predominantly referred to and most widely recognized in organizational literature' (Miller 2003). The focus of it was on group work, collaborative efforts among group members, and group development process. This was 
established essentially through the four stages of forming, storming, norming, and performing where the fifth was added as a result of research development in the field (Bonebright, 2010).

The research in this article was conducted on small group of graduate students studying business major at the college of business administration at the American University in the Emirates. The focus of this study was to explore the implementation and effect of the Tuckman's Model on a small group.

\section{REVIEW OF LITERATURE}

The study of group dynamics has become the attention of scholars and practitioners. Organizations across the group become interested in the development of groups. Therefore, there was a need to develop a model that can study group and team dynamics.

There are plethora of resources in the literature talked about groups and group development. One of the most cited across was the Tuckman's model. Most popular was the Tuckman (1965) and Tuckman and Jensen (1977). The research of google scholars has shown over 20 thousands sources referencing the model between the year of 2015 and 2019 at the time of conducting this research.

The model itself was described as a mean describing and studying groups, group dynamics and teams (Rickards \& Moger, 2000). The focus of the model is on group development. It is widely used by educators and practitioners in training programs and group analysis across organizations (Cassidy, 2007). It was a result of a therapy program from a meta-analysis study conducted on 50 studies of group development research of sequential development therapy groups (Tuckman, 1965; Cassidy, 2007).

In the year of 1969, there were data collected from groups of 174 meetings and 12 programs at a poverty program in Topeka, Kansas over a period of nineteen months resulted of seven stages of development (1) orientation, (2) catharsis, (3) focus, (4) action, (5) limbo, (6) testing, and (7) purposive (Tuckman \& Jensen, 1977). It was suggested later that Tuckman reduce it to four stages (Zurcher, 1969).

The result of a thorough literature review concluded with the a proposed model that focused on two dimensions: group development which included the dimension of 1) testing and dependence, (2) intragroup conflict, (3) development of group cohesion, and (4) functional role relatedness, and task activity which included the dimensions of (1) orientation to task, (2) emotional response to task demands, (3) open exchange of relevant interpretations, and (4) emergence of solutions. It was later summarized as "forming," "storming," "norming," and "performing," and a fifth stage "adjourning" was added later as a result of research development (Tuckman \& Jensen, 1977).

\section{OBJECTIVES OF THE STUDY}

The aim of this study was to answer the following questions:

1. How can the Tuckman Model be implemented in a class setting?

2. What are the implications of it on students on micro scale small groups?

\section{RESEARCH METHOD}

Data was collected on small group of graduate students studying a negotiation course at the college of business administration at the American university in the Emirates. Participants' age group ranged from 20 - 35 years old composed of a mixture of males and females. The sample size was relatively small and there was totally of 25 students composed of 17 males and 8 females. The highest percentage was Emirati students and the rest from different parts of the 
The Tuckman's Model Implementation, Effect, and Analysis \& the New Development of Jones LSI Model on a Small Group

Middle East region. This study was sufficient with the demographics provided and no other information was required at the time of this study.

Participants in class were divided into small group. Total number of groups was 5 and each group was composed of 5 participants. There was no specific instruction given to form a mixed group of females or males. Participants rather were given the liberty to choose their own members of the group.

Students were asked to perform a negotiation role-play simulation adopted from (Lewicki, Barry, \& Saunders, 2015). The title of the simulation is called The Used Car. Participants were asked to negotiate selling/purchasing a used car and were given 30 minutes. The description of the car is as follows: 2011 Volkswagen Jetta $\mathrm{S}$ sedan, 2.5L five-cylinder engine, automatic transmission, power steering, air conditioning, front-wheel drive, dual air bags, cruise control. Black with gray interior, power door locks, heated seats, power windows, and AM/FM/CD stereo. Mileage: 51,000 miles; radial tires expected to last another 30,000 miles. Fuel economy: $24 \mathrm{mpg}$ city, $31 \mathrm{mpg}$ highway; uses regular (87 octane) gasoline. No rust; dent on passenger door barely noticeable. Mechanically perfect except exhaust system, which may or may not last another 10,000 miles (costs $\$ 650$ to replace). Blue book values: retail, $\$ 12,100$; trade-in, $\$ 9,850$; private party, $\$ 10,500$. Car has been locally owned and driven (one owner). (Lewicki, Barry, \& Saunders, 2015). Both buyers and sellers live in the same city.

\section{OVERVIEW OF THE MODEL}

Tuckman Model is a development model created in 1965 by Bruce W. Tuckman and modified in 1977 in collaborative efforts of Tuckman and Mary Ann Conover Jensen. The new model is referred to as Tuckman and Jensen of 1977 revised model of small group development (Bonebright, 2010). The original model started with four stages: forming, storming, norming and performing. The fifth stage was added in the revised model: adjourning. The overall focus of the model is on group functioning within two dimensions: interpersonal relationships and task activity (Bonebright, 2010). The model was described as "to be used to describe developing groups for the next 20 years" (Tuckman 1984, 14).

\section{ANALYSIS OF THE MODEL}

\subsection{Forming}

The first stage of the model is forming. During this stage participants try to form their form group choosing their own members into 5 members in each group in this research paper. The number of participants in each group can vary depends on overall size of the participated group. This gives students a freedom of choice. It also encourages them to socialize with each other, getting to know one another, and introduce themselves to new members in the class they have not met previously. The forming is the initial and important stage in this model. This is simply because it can lead to create a success and harmony among team members or leads to the other direction of failure to achieve the desired outcome of the negotiation. Therefore, a great emphasis should be giving to this stage assuring participants that they are about to have fun while learning something new that can help them in their practical side of life. In this stage participants will experience a great deal of dependence through experiencing a task that has a value to their learning process. This stage develops participants' interpersonal skills, measures their behaviors, and enables their leadership skills. 


\subsection{Storming}

This is second stage of the model. During this stage participants will experience the agent of change of experiencing something new. This is due to the nature and complexity of the task. In this case, the negotiation case study plays the role of the agent of change due to the nature of it based on the description provided. The storming part happens in this stage is associated with emotions; behavior and conflict might arise as a result of such. This is simply because first student trying to familiarize themselves with each, that's what we refer to as self-understanding themselves. Second, students try to figure out how to work with each other and work with the case, that's what we refer to as self-skills abilities. Third, students might come to agreement and mostly disagreement, that what we refer to as the experienced agent of self-change. That's where the storming happens finding group members resisting each other. In this case, that's can be a process of stimulating their intellectuality. Tuckman $(1965,386)$ stated that 'group members become hostile toward one another and toward a therapist or trainer as a means of expressing their individuality and resisting the formation of group structure'.

\subsection{Norming}

This is the third stage of the model. This is where group members finds ways to creat harmony among each other. At this stage, group members try to accept each other's opinions and suggestions. The agent of time limitations plays a major role in this part. This is where you find a member of the group jumps out of no where and settles any issues happening among them reminding them that time is passing by and a solution should be presented. That's where we notice the best effective ways to work with each, coming up wit the best strategies and seal the deal of the case negotiated. There is less conflict happening in this stage and more mind streamlining of thoughts and ideas. That's where cohesion and harmony prevails.

\subsection{Performing}

This is the fourth stage of the model. In this stage group members start the actual act of negotiation trying to come up with the win-win situation. The actual work of implementation happens in this stage. It is referred to as 'functional role relatedness' (Tuckman 1965, 387). This is where participants get energized supporting each other trying to win and seal the deal. You would find interaction among participants in this stage is infused with actions and positivity. Group members tend to bend the roles during this stage for the benefit of all. The focus of all is channeled towards achieving the ultimate desired goal with the involvement and participation of all. However, you would find that participants assign one or two members in the group to negotiate on behalf of the group supported by all group members. That's where you find the whole group acting as problem solvers and wear their negotiation hats. That's because a robust structure was established in place based on putting personal benefits aside and success of the whole is the main goal. This is the stage of functionality, flexibility and performance.

\subsection{Adjourning}

This is a developed stage in the new Tuckman model of 1977. It is the fifth stage of the model. The focus of this stage is on the development of the team. Although you would find the usability of such a stage is less on a class level, but quite popular in an organizational level. This is where things are taken into the next stage after achieving the desired goals and objectives of the allocated task to the group. This is pretty much in use during restructuring in organizations. During this stage it is highly recommended celebrating the success of groups for their accomplishments, perseverance and hard work. That's where you make the group feel that they have achieved the overall success. In this scenario, celebrating the group negotiation would 
give a boost of confidence to the group. This, in turn, makes them even more motivated to negotiate another deal. It, sometimes, referred to as a mourning stage. This is simply because there is a lot of insecurity and ambiguity associated with the finishing of the task. Therefore, a transition plan is recommended during this stage to give sense of security and assurance to group members of the next stage. That, in turn, may reduce the sense of insecurity and ambiguity that might arise from this stage.

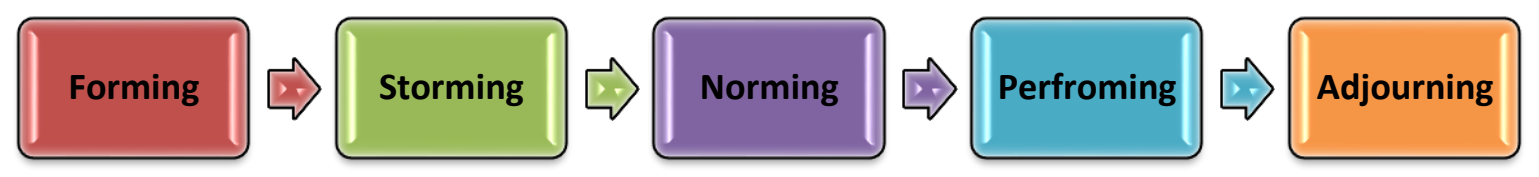

Figure 1 Tuckman and Jensen (1977) revised model of small group development.

\section{CONCLUSION}

The answers to the proposed questions in this study were discovered. The two questions were 1) how can the Tuckman Model be implemented in a class setting? and 2) what are the implication of it on students on a micro scale small group? It was found that the Tuckman Model can be implemented in a class setting with the stages except the last stage, adjourning, that might not be applicable in a negotiation role-play setting when conducted in class. However, it is highly relevant to corporate level and its implication can add a significant value when implemented. The implication that was found from the use of this model is that it is a great aid in monitoring student progress, skills, behavior, emotions, flexibility, adaptability and adjustability to different circumstances, different interaction with different cultures, and different case scenarios. It is, on a micro level, a tool to observe student's behavior, problem solving skills, critical thinking skills, management skills, and leadership attributes.

On a practical side, the analysis of this model come with a proposed model that might much more efficient when used on a smaller scale students or employees. The proposed new model depicted in the following:
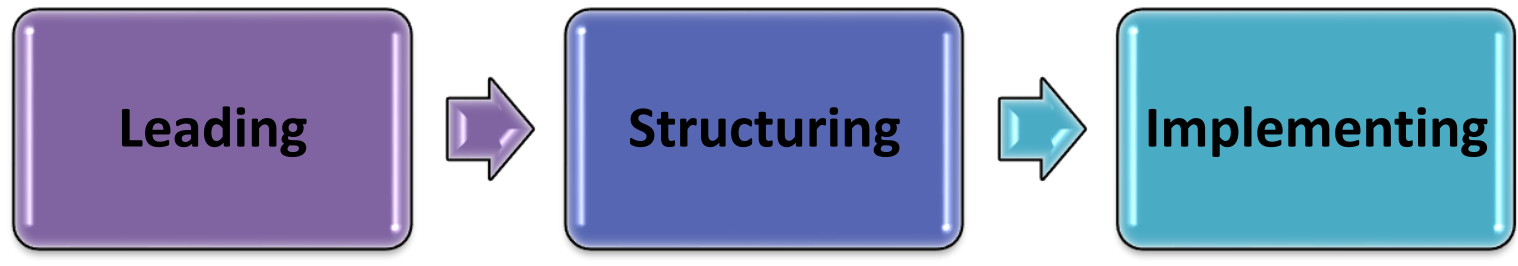

Figure 2 Jones LSI Model.

The new proposed model based on three essential elements: leading (L), structuring $(\mathrm{S})$ and implementing (I). The beginning part of the simulation starts with the leading. The leading part includes preparing students to the negotiation case. The orientation part with introduction to the case is happening during this stage. During this stage the leader of the activity is setting a goal to the group and time frame for accomplishing the task. The focus on this stage is on two dimensions: goals, tasks and time frame. The second part of this stage is the structuring. During this stage groups are formed randomly or by choice. This stage involves getting to know each other through proper introduction and socializing. It can act as a factor of developing social skills of individuals of the same group interacting with each as well as with other groups. The third part is the implementing stage. During this part, the actual implementation is happening. There are some challenges faced during this stage. Some of the most popular ones are conflicts among team, resistance to change, different opinions, different points of views, different 
perspectives, clash of thinking and point of views, emotional attitude, and change in behavior. Therefore, the first stage can eliminate most of these challenges through proper timely orientation taking into consideration that ample time might be needed to address most issues arise or might arise in the last stage. That being said setting goals, tasks, and time can play a significant role in speeding up the process of achievement and reducing conflict among participants.

The Jones LSI model can be implemented on a corporate level. It serves organizations that are experiencing a status quo where change is almost difficult to achieve. It can also be implemented on organizations that are experiencing losses in revenues. The model when implemented strategically and systemically it can create a paradigm shift in position organizations to the next level to even being able to compete on a larger scale from a macro and micro level. This model requires further testing. The aim of this new model when implemented is addressing the macro and micro layers in organizations: improving leadership in organizations, setting clear vision, reducing ambiguity, focusing on strategic thinking, improve critical thinking skills, problem solving skills, negotiation skills, reducing conflict, investigate the current structure, evaluate restructuring, and focus on implementation process achieving the desired mission. The ultimate goal is saving time, money and efforts addressing the main issues faced in organizations precisely and concisely.

\section{REFERENCES}

[1] Bonebright, D. A. (2010). 40 years of storming: a historical review of Tuckman's model of small group development. Human Resource Development International, 13(1), 111-120.

[2] Cassidy, K. (2007). Tuckman revisited: Proposing a new model of group development for practitioners.

[3] Lewicki, R., Barry, B. \& Saunders, D. M. 2015. Negotiations: Readings, exercises and cases (5th ed.). NY: McGraw Hill Higher Education.

[4] Miller, D. (2003). The stages of group development: A retrospective study of dynamic team processes. Canadian Journal of Administrative Sciences 20, no. 2: 121-43.

[5] Rickards, T., and S. Moger. (2000). Creative leadership processes in project team development: An alternative to Tuckman's stage model. British Journal of Management 11, no. 4: 273-83.

[6] Tuckman, B.W. (1965). Developmental sequence in small groups. Psychological Bulletin 65, no. 6: 384-99.

[7] Tuckman, B.W., and M.A. Jensen. (1977). Stages of small-group development revisited. Group and Organization Studies 2, no. 4: 419-27.

[8] Tuckman, B.W. (1984). Citation classic: Development sequence in small groups. Current Concerns 34: 14.

[9] Zurcher, L. A., Jr. (1969). Stages of development in poverty program neighborhood action committees. The Journal of Applied Behavioral Science, 5(2), 223-258. 